\title{
THE SOONER YOU DRINK IT ALL, THE MORE TIME YOU WILL HAVE THEREAFTER
}

\author{
Kirill Istomin
}

\begin{abstract}
Many reindeer herders of the Taz tundra have problems with excessive alcohol consumption and most of them are fully aware of these problems and the risks associated with them. In order to mitigate these risks, the reindeer herders have built up a range of strategies for alcohol consumption, which aim to limit this consumption to periods and circumstances when the damage (in economic and social terms) it produces is likely to be less significant, to shorten the periods of drinking (zapoi), and to limit the amount of alcohol available. For example, reindeer herders choose their camping places in such a way that the distance between them and the village is big enough to deter the herders from starting for the village in the middle of the night to bring vodka. Nowadays, this strategy seems to affect the migration patterns in important ways. Other strategies include limiting artificially the space available in a reindeer sledge (or on a snowmobile) when going to the village (which would limit the number of vodka bottles the herder can bring back), trying to consume (preferably in a big company of other herders) all the alcohol one has as soon as possible, and some others. The paper analyses these strategies using the theory of alcohol craving developed in the field of addiction psychology. It shows that the strategies can indeed be effective in the circumstances of the nomadic way of life, but they become maladaptive once nomads settle in villages.
\end{abstract}

Keywords: alcoholism, drinking strategies, Nenets, nomadism, reindeer herding, small peoples of the North

\section{INTRODUCTION}

Anthropological research on alcoholism and alcohol consumption among the aboriginal peoples of the Eurasian North has so far focused on three main topics. The first is the assessment of the scale of alcoholism and alcohol consumption among the native northerners, as well as its social, medical, and cultural consequences. Studies devoted to this topic are often based on quantitative medical, demographic, and sociological data and frequently take a rather alarmist perspective (Pivneva 2005; Nemtsov 1997; Bogoyavlenskiy 2010; Pika 1993). The second topic is the perception of alcohol and alcohol consumption by the people of different northern cultures and the analysis of different functions al- 
cohol plays in northern communities (Semke \& Bohan 2008; Sidorov \& Shubin 1994). Many papers in this collection also focus on this topic. Finally, quite a few studies, most of them published in Russian, try to explain the origin of alcoholism and heavy drinking among native northerners as a sociomedical problem. These studies frequently relate this problem to the social and economic policies and processes of the recent past - collectivisation, forced sedentarisation, social marginalisation due to the influx of population from the south, etc. - and, therefore, stress the responsibility of the dominant society for alcoholism and its consequences among the native northerners (Kozlov et al. 2002; Klokov 1996; Bogoyavlenskiy \& Pika 1991; Pivneva 2005).

Although I agree that all these topics are interesting from the academic perspective and important from the social and political ones, I would argue that an important component is missing. All these studies depict northern communities and their members as helpless victims of alcohol and of the social consequences of heavy drinking. This is true even for those few studies that observe some important social functions played by alcohol and, therefore, do not view it only in a negative light (see papers in this volume). Indeed, while alcohol consumption can sometimes have a positive impact, in the sense of establishing or strengthening social bonds, the negative consequences of excessive drinking are rather obvious and they definitely outweigh the positive impact. However, it is important to keep in mind that these negative consequences are also obvious for the native northerners themselves, and the natives can, and do, actively search for ways to mitigate them. This includes developing strategies for minimising alcohol consumption, consuming alcohol in less dangerous and harmful ways, minimising the potential of drunken conflicts, keeping economic losses related to drinking in check - in other words, everything that the native northerners themselves often refer to as 'knowing how to drink' (umet' pit'). This aspect of the alcohol-related practices - the different ways the native people themselves use to deal with their alcohol-related problems and urges - has deserved relatively little attention so far. On the other hand, as my fieldwork experience suggests, these 'practices of (non)drinking', as I would propose to name them, play a very important role in the everyday life of native northerners and can explain many aspects of their behaviour that would otherwise seem irrational and maladaptive.

In this paper I am going to describe and analyse the practices of (non) drinking, which I observed among Nenets reindeer herders of the Taz tundra in the southern part of the Gydan Peninsula (Tazovsky raion, Yamalo-Nenets Autonomous Okrug, Russia). The paper is based on the material that I collected during four fieldwork sessions, each lasting from 2 to 4 months (11 months in total), which I carried out among reindeer herders in the reindeer herding 
enterprise Sovkhoz Tazovsky between 2006 and 2012. During these fieldwork sessions I joined the migration of reindeer herders, taking an active part in their day-to-day activities and performing observations, among others, of their drinking practices. Since I do not enjoy drinking alcohol, I did not participate in the drinking parties myself, and in the beginning this created a feeling of uneasiness among the herders. However, by the end of the first fieldwork session, the herders got used to my not drinking alcohol (in fact, a rumour was spread that I was 'coded', i.e. made a non-drinker by medical means) and their feeling of anxiety disappeared. They easily consumed alcohol in my presence, and they willingly replied to my questions about how and when one can avoid drinking. Since I do not speak Nenets, I communicated with the herders in Russian. The information obtained from interviews as well as my observations were recorded in the form of field notes. I did not use a tape recorder, because the herders clearly felt uneasy about being recorded and often directly prohibited my use of it. As alcoholism and drinking habits are sensitive topics, I have chosen not to cite my informants by name but have marked their statements by the place and year only.

The principal aim of the analysis of the collected data offered in this paper is to establish why and under which conditions the practices of (non)drinking work or fail to work. In other words, I am going to establish what exactly makes these practices effective in preventing excessive drinking and which factors limit their effectiveness. In formulating my aim in this particular way, I consciously remove the questions of meaning and interpretation, which are so dear to the hearts of modern anthropologists, from the focus of my analysis. This does not mean that I am going to ignore these questions altogether: indeed, as I will try to show, the herders' understanding of alcohol and their own relation to it is a part of the mechanism that makes the practices effective in some, and ineffective in other, situations. My aim in this paper is to explain the practices rather than to interpret them, to show how they work, rather than to establish what they are 'in a sense'. This choice is made on purely practical grounds: I think that at this particular moment, an understanding of the mechanisms that support the practices of (non)drinking is more useful for the population of my field site, including my informants, than an account of different senses and interpretations related to them. This decision regarding my paper has informed the choice of the theoretical background, as will be described in the next section.

The discussion in this paper will proceed as follows. Firstly, I will dwell upon the theoretical background used in this paper, with a special focus on the mechanisms behind the so-called alcohol craving, one of the main components of alcohol dependency, which, as I will try to demonstrate, is exactly what the practices of (non)drinking are dealing with. Then, using this information as 
a background, I will describe the practices of (non)drinking among the reindeer herders and explain why, when, and under which conditions they can be effective. Finally, I will discuss how these practices affect the behaviour of reindeer herders in different situations, and assess their relative benefits and costs.

\section{IN SEARCH OF A THEORETICAL BASE: PHENOMENOLOGY OF PSYCHOLOGICAL ALCOHOL DEPENDENCY}

Cross-cultural research on alcoholism was initiated more than 40 years ago with the classical work, Drunken Comportment, by Craig MacAndrew and Robert B. Edgerton (2003 [1969]). In this seminal work the authors demonstrate that drunken behaviour varies greatly between cultures and social settings and, therefore, there is no such thing as universal drunken behaviour and universal effects of alcohol on humans. Both the short-term and long-term effects of drinking are produced by ethanol, which has a particular impact on the human brain. The authors, therefore, urge to incorporate cultural and social factors into the previously purely medico-biological models of alcohol-dependent behaviour and alcohol addiction. They seem to hope that their work would eventually lead to a broad interdisciplinary cooperation between anthropologists, sociologists, physiologists, and medical practitioners in providing a theoretical explanation of the phenomenon of alcoholism and mitigating its consequences.

Unfortunately, just as with many other interdisciplinary research projects involving anthropologists, this project has fallen victim to the interpretative turn that occurred in anthropology beginning in the late 1970s. Instead of working together with natural scientists on broad models to explain the impact of alcohol on humans, anthropologists redirected their attention to uncovering the meaning of alcohol and the values associated with it. Most anthropological research on alcoholism up until now has been of this type, and it has yielded some important achievements (see Chrzan 2013; McKnight 2002). Unfortunately, these achievements were of little interest for physiologists and medical workers seeking to build up an explanatory model for the phenomenon. On the other hand, physiologists and medical workers also lacked theoretical and methodological resources to incorporate cross-cultural data into their model. Therefore, the trans-cultural addiction studies (as the physiological and medical cross-cultural research on alcoholism came to be labelled) consisted mainly in collecting statistical data on alcohol consumption, alcohol-related diseases, alcohol-induced violence, and endogenic alcohol production across cultural groups, and then running ANOVA models in order to check if cultural identity was an important predictor of these social and medical problems (Semke \& 
Bohan 2008). Although most of the studies demonstrated a significant difference between cultures in all the mentioned indexes (and, therefore, the role of culture as a predictor of alcohol-related problems was proven beyond a reasonable doubt), no theoretical account explaining how culture is related to alcoholism has so far been offered. It was only recently, after dissatisfaction with the interpretative stance began to spread amongst anthropologists, that interest towards joint explanatory models, as envisaged in the Drunken Comportment, started to get re-established (Glasser 2013 [2011]).

Despite this recent development, we still have very little in the sense of a theory that can be used to analyse the mechanisms and effects (in a physiological, psychological, economic or behavioural sense) of the cultural-specific practices related to alcohol consumption, rather than the cultural meaning and significance of these practices. Since this particular work focuses on mechanisms and effects rather than on meaning and significance, this lack of theory represents a serious problem. The best way to deal with this problem is to follow the advice of John Berry and colleagues given in their classic introductory overview of cross-cultural psychology (Berry et al. 2002): to start with a general model produced by a synthesising science (human biology, general psychology, physiology, etc.) and describing the relevant phenomenon on the level of human species, to look for parts in this model in which culture can play a variation, and to probe into whether the cross-cultural variation in any of these parts can explain the observed phenomena.

It seems to me that the most appropriate general model into which the practices of (non)drinking can be incorporated as 'variation players' in order to explain mechanisms, reasons, and conditions of their (non)effectiveness, is the model explaining mechanisms of alcohol craving. Indeed, it is commonly understood now that alcohol craving plays a very central role in alcohol dependency, and that no explanation of this dependency based solely on the metabolic effects of alcohol is possible (Zavjalov 1990). Unfortunately, this understanding, which would sound self-evident for an anthropologist, represents a relatively recent achievement for psychological and physiological addiction studies, which traditionally detested any phenomenological entities as explanatory variables; accordingly, it was only relatively recently that the psycho-physiological mechanisms behind alcohol craving became a particular focus of studies (Anton 2000).

However, even before the special studies on craving were started, many specialists on alcohol dependency noticed that alcohol craving and the behaviour it produced had much in common with the so called obsessive-compulsive syndrome (Modell et al. 1992a). For a long time, the similarities between the two psychiatric conditions were believed to be only superficial. Specifically, it was pointed out that the two conditions had very different etiologies. Furthermore, 
it was believed that an alcoholic finds a certain pleasure in his or her drinking habits, which makes him/her phenomenologically very different to a person suffering from the obsessive-compulsive syndrome. The latter does suffer from his/her condition in the very literal sense of this word (ibid.). However, the early studies on phenomenology and behaviour symptomatic of the craving for alcohol, performed at the end of the 1980s and beginning of the 1990s, immediately showed that the similarities between the two conditions were deeper than believed (Modell et al. 1992a; Anton 2000). So deep were these similarities that the so-called obsessive-compulsive scale, the basic instrument used by psychiatrists to assess the severity of the obsessive-compulsive syndrome, as well as to plan its treatment and predict its outcome, could easily be adopted to assess the severity of alcohol-related problems and predict the outcome of their treatment (Modell et al. 1992b). Furthermore, recent brain imagining studies indicate striking similarities in brain physiology of the two conditions: the patients with a severe alcohol craving have basically the same abnormalities of brain activation in comparison to healthy people as the patients with the obsessive-compulsive syndrome (Anton 2000). All this suggests that although the etiologies of the two conditions are indeed different (which excludes the classification of alcoholism as a form of OCD), their pathological mechanisms and phenomenology, at least as far as the psychiatric and neurological side of alcoholism is concerned, are very close if not similar.

Thus alcohol craving is similar to OCD in the respect that it has two principal components (Penzel 2000). The first is intrusive thoughts that focus, in this case, on the alcoholic beverages and the process of consuming them. These thoughts, which are difficult or even impossible to resist or expunge from the mind, produce uneasiness and anxiety often also anger and fear. The second is a compulsive behaviour aimed to reduce the anxiety by means of active search for obtaining and consuming alcoholic beverages. This behaviour is compulsive because, in contrast to what was believed before the late $1980 \mathrm{~s}$, alcoholics neither get nor expect any gratification from it. On the contrary, most of them are fully aware of its irrational and destructive nature and can foresee its negative effects on their health and social standing. They, however, feel compelled to engage in this behaviour as the only escape from their obsessive thoughts, despite being fully aware that the relief is only temporary and that the intrusive thoughts will soon return. Therefore, the sufferers engage in the compulsive behaviour against their own will, often feeling helpless and depressed by the negative consequences of this very behaviour. Numerous stories about people committing suicide because they were tired of drinking confirm this fact.

One interesting fact about the obsessive-compulsive syndrome is that both the intrusive thoughts and the anxiety they provoke can often be greatly re- 
duced - or even disappear - in situations where the compulsive behaviour becomes physically impossible or when the person genuinely believes that he or she cannot indulge in such behaviour (ibid.). This is as if the disease - which can normally easily break the person's will and powerfully compel him or her to behave in a certain way - gives up and stops torturing its victim, if he or she simply cannot behave as compelled, no matter how he or she wanted to. Thus, an excessive drinker does not usually suffer from the intrusive thoughts about alcohol if he or she is in a forest, or alone at sea, where buying and consuming alcoholic beverages is impossible. However, the intrusive thoughts immediately come back once the excessive drinker returns to a settlement or ashore and alcohol becomes available again. This is the main reason why the forced deprivation of alcohol by means of involuntary confinement is a very ineffective method of treating alcohol dependency. While patients may feel good during the confinement and can say they do not have any desire for alcohol (and indeed subjectively feel so), the craving immediately returns once the patients are released from their confinement and alcohol becomes available again.

One can immediately see where culture can 'play a variation' in this model. Being a powerful instrument of interpreting the world and the situations encountered by a person, culture can influence personal beliefs about what is and what is not possible in any particular situation. Furthermore, being a powerful instrument shaping human behaviour, culture can guide a person into situations with particular sets of perceived possibilities. Therefore, cultural practices can, in theory, manipulate alcohol craving by guiding a person into situations with a specific perceived availability of alcohol. Since alcohol craving is the most important factor in alcohol consumption, this manipulation can be a very effective way to stimulate or prevent alcohol consumption. In the following sections I will try to demonstrate that the practices of (non)drinking among the Nenets indeed utilise exactly this mechanism.

\section{PRACTICES OF (NON)DRINKING AMONG THE TAZ NENETS}

The Nenets are indigenous people populating a huge territory of tundra and northern taiga of the Eurasian North, from the Kola Peninsula in the west to the Taimyr Peninsula in the east. During the last Russian Census (2010), approximately 45,000 people indicated Nenets as their ethnic background, which makes the Nenets numerically the biggest of the small-numbered aboriginal peoples of Russia. Traditionally the Nenets have been nomadic reindeer herders and almost half of them (about 20,000) still negotiate the tundra and taiga with reindeer herds. The Taz Nenets, which are the primary focus in this 
paper, are a group of the Nenets living in the so-called Taz tundra, the southern part of the Gydan Peninsula. Administratively, the Taz tundra represents the southern part of the Tazovsky raion of the Yamalo-Nenets Autonomous Okrug of the Russian Federation. The town of Tazovsky with a predominantly Russian population of approximately 6000 is the administrative centre of the region, while the rest of the territory (except for the small village of Gas Sale) is populated almost exclusively by nomadic Nenets, who account for almost half of the whole population of the raion.

A popular opinion in Russia (and, up to a certain degree, around the world) is that native Siberians are excessive drinkers. This concerns also (or maybe even particularly) reindeer herders, who are famous for their consumption of large amounts of strong alcohol every time they come to the village. This is what one Russian inhabitant of the Tazovsky village boldly stated to the author:

Seeing a sober reindeer herder is a very rare occasion and we do not welcome it, because the only thing such a sober reindeer herder would do is beg for a bottle of vodka or money to buy one. Reindeer herders are sober only when they do not have money to get drunk. (personal communication, Tazovsky 2006)

This popular opinion is reflected in some academic works (e.g. Semke \& Bohan 2008), which actually state beyond any doubt that alcoholism (in the sense of physiological dependency) is widespread among native tundra nomads.

Any sufficiently careful participant observation of the life of reindeer herders immediately reveals, however, that this popular opinion is wrong. Indeed, as it was already mentioned by Anatoly Mukhachev (2001), Nenets reindeer herders drink surprisingly little, particularly if compared to the local settled and predominantly Russian population. Thus, the reindeer herders do not drink at all during the late spring, summer and early autumn, when travelling in the tundra is restricted, settlements are inaccessible for tundra dwellers, and alcohol is simply not available. This period of abstinence lasts from 4 to 6 months and can be interrupted by one or two periods of drinking that usually last for 2 or 3 days, and follow an occasional arrival of a helicopter with cargo from the village or a visit by a travelling tundra merchant (kommersant). In winter, alcohol consumption also depends on accessibility to the settlements, which, in turn, depends on the weather, the distance to a settlement from the current position of the herders' camp, as well as the means of transport (a snowmobile, a reindeer sledge) the herders possess. All these factors vary unpredictably and, therefore, the periods of alcohol availability, which can last a few weeks, get replaced by equally long periods when alcohol is unavailable. In other words, alcohol is simply unavailable for the reindeer herders for the greater part of 
the year and, therefore, they have to stay sober most of the time. I would definitely not argue that alcoholics (meaning the people with a physiological rather than psychological dependency on alcohol) are absent among the Nenets, but their need to consume alcohol regularly and effectively prevents them from pursuing the traditional nomadic way of life and binds them to a settlement. Alcoholics cannot live in the tundra, due to the scarcity of alcohol there. Indeed, the majority of herders I observed seemed to be able to stand long periods of abstinence with little effort.

On the other hand, when alcohol is available, the reindeer herders tend to consume it intensively and in large quantities. What is more important, this intensive alcohol consumption has some definite traits of obsessive compulsiveness. Indeed, as many ethnographies mention, and as many of my colleagues who have worked with the Nenets can attest, the herders change profoundly and abruptly once they come to a settlement or migrate to a place where the settlement is in close proximity. In these situations, many herders first become observably anxious and their anxiety grows as the perspectives of obtaining alcohol become more real. The urge to get and consume alcohol comes a bit later. In many cases I observed how the herders tried to resist this urge for some time, which visibly caused acute suffering. It was rather hard and surprising to see how people who had just spent many weeks far away from the village in a balanced and cheerful mood, suddenly became depressed, angry, ceased to sleep normally, abstained from food. Finally they gave up and departed for the village, often secretly and at night, to spend several days or even weeks drinking there. Only when their physical or economic conditions dictated that they stop, would they return to the camp, exhausted and intoxicated. However, after several days of recovery, their anxiety came back and, after another few days, they surrendered to it again. It is easy to see that this pattern corresponds closely to that of obsessive-compulsive syndrome, which gets temporarily offset by the impossibility of the compulsive behaviour, but returns every time a change in the situation makes this behaviour possible. This is further supported by the fact that, as far as I could see, only young reindeer herders could sometimes express positive emotions about the prospect of getting access to and consuming alcohol. This is probably related to the fact that socialising, which accompanies and gets facilitated by the alcohol consumption, is more valuable to them and its value sometimes outweighs the probable economic losses and social risks related to drinking. Among older reindeer herders, the emotions were more complex: while they actively sought the possibility to consume alcohol, if they believed that this possibility existed, they did not seem to enjoy it at all. Rather, they saw the seeking and consuming of alcohol as a kind of duty that they had to perform against their will, simply because avoiding it was impossible. This 
clearly compulsive-obsessive character of alcohol consumption further supports the choice of the alcohol craving model, explaining the practices of non-drinking found among the Nenets.

The best place to start describing these practices is probably the observation many ethnographers are familiar with, not only among the Nenets, but also among other indigenous peoples of the Russian North: the observation that native northerners almost never store alcohol for later consumption, but try to consume all the alcohol they have immediately, in the shortest possible period of time. In this period, the amount of alcohol consumed by a single person per unit of time can be very high and exceed all reasonable norms both from psychological and medical points of view. Furthermore, it is common among the Nenets to invite others - relatives and friends - to take part in the alcohol consumption, and the number of people invited is usually proportional to the amount of alcohol. I have never observed Nenets herders consuming alcohol alone, probably because they live in compact groups (nomadic camps called okolodok), where sharing is obligatory. This sharing serves, of course, various social and cultural functions. Still, in the case of sharing alcohol, it is remarkable, first of all, that it is often shared with people from other nomadic camps, who are specially invited to take part in the consumption. Secondly, it is interesting that the Nenets themselves often rationalise their behaviour in terms of speeding up the alcohol consumption: quite a common statement would be something like, "Jelya has brought so much vodka that it would take us too long to drink it up; we should call the third brigade to help us!" (personal communication, Taz tundra 2006) Statements like these usually take for granted the need to consume all the available alcohol as fast as possible. When asked to explain this need, Nenets informants usually say that drinking takes time from work and, which is probably the most interesting statement, from rest. The phrase by one of the informants that I made the title of my paper provides a particularly good example: "The sooner you drink it all, the more time you will have thereafter: to sleep if you like, to chat if you like, to work if you like." (personal communication, Taz tundra 2010) It should be clear that this statement indeed makes much sense: one important negative consequence of consuming a considerable amount of alcohol is the time lost while drinking and during the recovery period. Increasing the speed of consumption, achieved, among other things, by increasing the number of consumers, can indeed be one of the ways to minimise this loss. Of course, limiting the amount of alcohol could look like a more rational way to achieve the same end from both medical and economic points of view. However, if, as I argued before, alcohol consumption is a compulsive behaviour, this alternative can simply be unavailable for the 
herders, while the strategy 'drink it all as soon as possible' can have, besides the economic, also a psychological payoff. The following story can explain why.

During one of my fieldwork sessions, I got stuck in a reindeer herding camp where all the males were completely drunk for several days after a visit to a village and, for about five days, all the work, including the daily rounding up of the reindeer herd, had to be performed by three women. It should be noted that among the tundra Nenets excessive drinking represents mostly male behaviour. This does not mean that women cannot drink excessively, but, just as in the case of physiological alcohol dependency, abuse of alcohol by women seems to be incompatible with the nomadic way of life and the traditional system of labour sharing between sexes. In this system, women have to perform most of the day-to-day subsistence tasks, such as making firewood, keeping the chum (nomadic tent) warm, providing water, cooking food, etc. Their failure to perform these duties, even temporarily, due to alcohol abuse, immediately makes life in the tundra impossible. It is commonly believed that families where women start to drink excessively should abandon the nomadic way of life and settle, because otherwise they would simply get frozen to death. Although the excessive drinking by males can also lead to economic breakdown of the family through loss of reindeer, it does not put the lives of the family members into immediate danger. In the situation described, however, the economic prospects of the whole nomadic camp were endangered, because the three sober women, despite my doing the best to help them, could not manage all the work of pasturing that is normally performed by a team of four skilled men. It was clear that we were going to lose quite a few reindeer if the males would not recover and go to search for them. I therefore proposed to the women to steal the remaining alcohol from the males and hide it. I said that this would force the males to recover and start working. I argued that once they would recollect the dispersed herd and, therefore, decrease the threat of reindeer loss, we could return the alcohol to them and let them finish it in peace. The women, however, explained to me that the thing I was proposing was something that young stupid girls would usually try, while wise adult women would know that doing that was too dangerous:

You see, males can stop drinking only if they are sure that there is no vodka in the camp. To be so sure, they should be $100 \%$ certain that there is no vodka hidden by us. If, when they ran out of vodka, they would suspect that there can be some extra bottles hidden by us, they would never calm down. They would keep asking us if we really do not have vodka and so they would continue thinking about vodka all the time and finally would leave for the village again. (personal communication, Taz tundra 2006) 
The only way to avoid this danger, the women say, is never to steal and hide vodka and encourage the males to drink everything they have as soon as possible and in a company as big as possible. Indeed, the males know that knowledgeable women would adopt this strategy for their own good and, therefore, they would know that if they cannot find any vodka then there is indeed no vodka in the camp.

These statements clearly indicate that the described practice is related to the effect the perceived impossibility of compulsive behaviour produces on the obsessive anxiety (see the theoretical section of this paper). In order for this effect to take place, however, one should genuinely believe that he or she cannot indulge in the compulsive behaviour. The physical absence of alcohol in a reachable proximity, if the person believes in this absence, is indeed a good ground to think that alcohol consumption is physically impossible. However, the absence of alcohol in the camp is obviously not enough here: one should also genuinely believe that the probable sources of alcohol outside the camp are also inaccessible. These include, first of all, the settlement and, secondly, other herders who are likely to have vodka and be willing to share it (note that the practice described above presupposes sharing of vodka). The easiest way to render the settlements inaccessible is, of course, by moving away from them. Indeed, reindeer herders uniformly stated that one should not camp too close to the settlement and explained this by three factors: poachers, dogs, and the danger of excessive drinking. Interestingly, the last factor was the most operative in defining the distance from the village. The herders explained it was a general rule that one should camp so far from the village that there would be no temptation to go there in the middle of the night to buy vodka. In other words, one should be far enough away from the village to perceive going there as a big journey that is likely to last more than a day. As some of them stated, those who fail to obey this rule and camp closer to the village end up losing their reindeer, because they cannot stop drinking and let the animals wander on their own accord. Obeying this rule, on the other hand, would also solve the problem of poachers and dogs, because neither usually go further away from the village than a half-day trip.

Observing how this rule is obeyed by the herders reveals much about their perception of distance and the notion of journey. Thus, it is intuitively clear that the temptation to leave for vodka during the night should essentially depend on the type of transport available. For example, given the same distance between the village and the camp, this temptation should be stronger among those herders who have snowmobiles, in comparison to those who do not have them and have to rely exclusively on reindeer sledges. Indeed, the former can cover a longer distance in a short time. We can suppose, therefore, that poor 
herders - those who do not have snowmobiles - have to camp closer to the village. Indeed, that is exactly what observations show us. Thus, when the village of Tazovsky gets surrounded by reindeer herders' camps in winter, the camps without snowmobiles always make up the inner circle, which is surrounded by the outer circle of camps with snowmobiles. Although this fact admittedly can have a number of explanations, the reindeer herders do refer, among others, to the factor of alcohol avoidance: "Mikhail can live close to the village - he does not have a snowmobile to go for vodka all the time." (Semyon Habd'u, Taz tundra, 2009)

Another interesting example in defining a safe distance from the village can be the role of the Taz River, which is one of the major rivers of Western Siberia. In its lower course, it represents a peculiar labyrinth of islands and flows about 30 to $35 \mathrm{~km}$ wide. In winter, the interconnected flows turn into excellent snowmobile roads, but navigating them requires a good knowledge of the spatial layout of the labyrinth. Reindeer herders usually lack this knowledge and, when crossing the Taz, they usually follow the tracks left by the semi-settled Nenets fishermen, who live and fish in the Taz River all year round. The town of Tazovsky is situated on the left bank of the Taz. An interesting fact is that the reindeer herders believe the place on the right bank of the Taz, just on the opposite side from the village, to be very good for winter camping: they hold that this place is both close enough and distant enough from the village and, in fact, compete with each other for the right to camp there. However, the left bank of the river at a distance of $30-35 \mathrm{~km}$ from the village is believed to be too near for safe camping. This distance, which can be covered by a snowmobile in about two hours, is believed to represent no challenge that could discourage one to go and buy alcohol. It seems like crossing the Taz River, which can in fact take a shorter time than covering the same distance on the shore due to a much better travelling surface, is still perceived as a big journey, solely due to it being fairly unusual for the herders and being related to reliance on others' travelling knowledge. This is enough to assure the herders that the alcohol on the opposite side of the river is not readily accessible and, therefore, to deal with their obsessive thoughts.

Dealing with other herders as potential sources of alcohol is less straightforward. The first thing to be mentioned here is that the reindeer herders, on their way to and from the village, tend to use established trails made by many people who travelled such tracks before them. These trails tend to go along frozen rivers and hill ranges, which makes travelling conditions better and allows the preservation of petrol. The same tracks, therefore, tend to be used from year to year. Many reindeer herders have told me that it is common wisdom not to camp along these trails. The danger of economic loss due to excessive 
drinking was offered as justification. They said that those who camp near the trail are going to have too many visitors and about half of them - those who are travelling back from the village - are going to come with alcohol, which could be enough to keep the hosts drunk most of the time, and certainly much longer than would be economically safe. On the other hand, despite such wisdom, there are reindeer herders in the Taz tundra who camp near the tracks and, if I am not mistaken, do this quite deliberately. Such people play an important role in tundra life, because their chums (nomadic tents) are widely used by other herders for night stays during their journeys to and from the village; I would reiterate that many herders try to choose camping places in such a way that these journeys would take more than a day. For this important role in tundrato-village communication, the road-keepers are rewarded by frequent and easy access to alcohol, which is, of course, a poor asset in my opinion as well as in the opinion of many herders. On the other hand, the road-keepers also get access to certain supplies, such as bread, butter, pasta, tea, etc., that the travellers bring from the village and often leave, in small quantities, in gratitude for the night's stay. For the road-keepers, who are mostly very poor, this could be a significant reward that can justify their strategy. Further research is needed, however, in order to clarify this.

Although avoidance of camping near the tracks is clearly a strategy to avoid meeting a herder with alcohol to share, in other situations the herders clearly seek to meet such a person. Thus, once reindeer herders hear that someone from a camp nearby has just returned from the village, almost all of them immediately recall a variety of important and urgent grounds to visit that camp. As far as I can judge, this is a rule with very few exceptions and it can represent a compulsive reaction to the availability of alcohol in the proximity. On the other hand, it is exactly the uniformity of this reaction that almost guarantees that any amount of alcohol that is transported from the village to the tundra gets consumed in a very short time, which, as I have argued above, is likely to have a number of positive economic as well as psychological consequences. Another probable effect is that it makes it irrational to buy alcohol in large quantities. Indeed, it is easy to see that once the amount of alcohol one buys and transports to the tundra exceeds a certain threshold, every extra unit of alcohol bought would only increase the free-loading of others rather than bring any sort of satisfaction or profit to the buyer. This brings us to the final class of practices I would like to discuss: the practices that limit the amount of alcohol one buys in the settlement and brings to the tundra.

These practices are, as it seems, aimed to deal with the urge to buy as much alcohol as possible during every visit to the village, sometimes at the expense of other goods or services. The most basic and the most important of them is 
the famous 'iron rule': buy other goods first and alcohol later. In accordance with this rule, a reindeer herder who comes to the village should first buy all the products he or she needs apart from alcohol and pack these products on the sledge. Only when these products are bought and packed, can one proceed to buy alcohol. This rule limits the amount of alcohol one can buy, first of all, by decreasing the funds available for buying it. It also limits the amount of alcohol one can transport to the tundra by limiting the available space on the sledge. The latter is probably even more important than the former, because one can often raise money by borrowing it from others, selling private belongings, or even reindeer, or by small-scale earnings, for example, by giving the village people a ride on a reindeer sledge. However, one cannot increase the carrying capacity of one's sledge and/or the power of one's snowmobile engine. Hence, some reindeer herders go even further by artificially decreasing the carrying capacity of their sledges when going to the village. Thus I have observed several instances when the herders who left for the village loaded their sledges with heavy and sizable items such as fishing nets or sledge runners, which are very valuable in the tundra but cannot be of any value in the village. The herders explained that these items would be transported to the village and then back to the camp and that their main purpose was to limit the amount of goods one can buy in the village - since one would hardly throw away a new net or a sledge runner; one would rather limit one's greed for goods. Since food and manufactured goods are always bought first and vodka later, one can presume that the main function of this unnecessary cargo is to limit the amount of vodka.

\section{THE CONDITIONS OF EFFECTIVENESS AND LIMITATIONS OF THE PRACTICES OF (NON)DRINKING}

All the practices of (non)drinking that have been discussed so far make perfect sense given that their function is indeed to help cope with or eliminate the anxiety related to the obsessive-compulsive mechanisms of alcohol craving. This explanation, however, clearly points to the objective limitations of these practices. The most important of them is quite obvious: these practices are designed in fact not so much to deal with excessive drinking but rather to minimise its economic and/or social consequences. In this sense, the Nenets are quite similar to some modern psychiatrists, who believe that, for many psychiatric syndromes, modern medicine should not so much look for ways to eliminate the symptoms (which is in many cases impossible anyway), but rather help patients to adapt to them and, by so doing, minimise their negative consequences. 
Secondly, as the analysis clearly suggests, such practices can only be effective if two important preconditions are met. First of all, the supply of alcohol should be predictable and limited to a few geographic locations (settlements and trading posts), which are relatively distant from each other. Secondly, people who rely on the strategies should have a nomadic way of life. Indeed, only if these two preconditions are in place can one regulate the availability of alcohol by physically moving towards or away from the centres of its supply. If the preconditions are not met and the regulation of alcohol availability is impossible, the practices can become profoundly maladaptive. For example, for former reindeer herders who settle in villages, hardly anything can be more devastating than the habit of consuming all the available alcohol in the shortest amount of time. I would even cautiously suppose that the terrible alcohol-related problems usually experienced by former reindeer herders - the problems which often cause their death - can at least partly be explained by their failure to abandon the tundra drinking practices in their new settings. Similarly, little can be more dangerous and devastating for the tundra dwellers than travelling merchants (kommersanty) who bring alcohol to the tundra and, therefore, make it available in geographical locations it was not available before. In a way, similar to the herders' settling in a village, the arrival of a merchant immediately renders the practice of consuming all available alcohol as fast as possible maladaptive. Thanks to this practice, the herders are ideal clients for an alcohol-selling merchant: they can consume almost any amount of alcohol in almost no time and, furthermore, pay almost any price for it. For the herders, on the other hand, the arrival of such merchants always means a great deal of damage in both economic and medical terms. Historical literature on the Nenets is full of examples describing how herders sold their whole herds and sometimes even their individual freedom to merchants, because they could not stop consuming the alcohol merchants made constantly available for them (see, for example, Islavin 1847; Maksimov 1984; Kertselli 1911).

Furthermore, it may seem rather ironic, but it appears as if the described practices of (non)drinking - the reindeer herders' way to deal with alcoholrelated problems - are largely responsible for the popular image of Nenets herders as alcoholics consuming much more alcohol than the settled villagers. As I tried to demonstrate in this paper, this image is wrong. However, it can hardly be surprising, given that most outsiders observe Nenets herders only in the village or during short visits to the herders' camps. Since anyone who comes to a camp from the village is supposed to bring some village goods including alcohol, all these observations are made in situations when a certain amount of alcohol is available and, in accordance with the described practice, should be rapidly consumed. On the other hand, if one sees a group of people consuming 
large quantities of alcohol in almost no time, it is only natural for him or her to conclude that such people drink heavily.

As all these examples show, the practices of (non)drinking are a tricky cultural asset that can be both a blessing and a curse.

\section{CONCLUSIONS}

Many studies that focus on the problem of excessive alcohol consumption among the Russian native northerners depict these people as helpless victims of their alcohol craving. However, the native northerners are certainly fully aware of their alcohol-related problems and the damage their excessive drinking causes to them, both in medical and economic terms. In order to avoid or at least decrease this damage, many native northerners seem to resort to particular behavioural strategies, which I suggest to name the practices of (non)drinking. The prefix 'non' is written in brackets here, because the aim of these practices is not so much to help people stop drinking, but rather to decrease the economic and social damage related to drinking. Admittedly, decreasing the amount of alcohol consumed is one way to achieve this aim. However, there can be other ways, and some of them include, in fact, a temporary intensification of alcohol consumption.

The practices of (non)drinking employed by the Taz Nenets are a good example. It seems like these practices represent an attempt to regulate the alcohol craving by playing with one particular peculiarity of this craving, which it has in common with the obsessive-compulsive syndrome: this craving for alcohol decreases greatly or even disappears completely in a situation where a person genuinely believes that alcohol is inaccessible and cannot be rendered accessible right now, whatever efforts one would invest. In order to regulate their alcohol craving, the Nenets try to create situations in which alcohol is physically inaccessible to them (or at least they genuinely believe it to be so), and stay in such situations for as long as possible. This is achieved by camping far away from the settlements (the sources of alcohol), by artificially limiting the carrying capacity of the means of transportation used for visiting settlements, and by avoiding camping close to the tracks of other herders who go to and from the settlements. In the cases where alcohol occasionally still gets to the camp (which happens relatively frequently due to visitors, tundra merchants, and trips to the settlements that herders have to take to buy necessary supplies, get medical and certain social services, sell their goods and/or cash their salary), the common practice is to consume it as fast as possible and in as big a company as possible. This causes a short-term intensification of drinking, yet 
still limits the damage caused by alcohol by shortening the period of time spent on drinking and, therefore, decreasing the economic losses.

These practices of (non)drinking seem to be rather effective: contrary to popular opinion, Nenets reindeer herders consume less alcohol than most settled villagers, native or otherwise. However, as it is not difficult to notice, these practices can function only in specific geographic and cultural settings, where sources of alcohol are limited to sparsely situated settlements and people, being nomads, can regulate their access to these sources by moving towards or away from them. If geographic or cultural settings change, the practices can suddenly become maladaptive. Thus it can be supposed that one of the reasons reindeer herders often drink themselves to death after settling in a village is that they continue, deliberately or not, to follow the tundra practice of drinking all the available alcohol as soon as possible. Of course, following this practice is a rather bad idea in a village where the supply of alcohol is limitless. Similarly, tundra merchants who bring large quantities of alcohol to the tundra can inflict serious damage on the reindeer herders' economy, because the herders who resort to the drink-it-all strategy cannot help but consume all the alcohol the merchants bring.

In short, the practices of (non)drinking represent a response by the reindeer herders to their own alcohol-related problems, which is adapted to the specific geographic and cultural settings of reindeer-herding nomadism. They are inapplicable in other settings. As many settled Nenets say, reindeer herders who settle in a village should learn many things and learning how to drink while living in a village features highly among them. I hope that the analysis made in this paper sheds some light on the source and nature of this particular problem and, therefore, helps to mitigate it.

\section{MANUSCRIPT SOURCES}

Fieldwork materials from the years 2006, 2009 and 2010 in possession of the author.

\section{REFERENCES}

Anton, Raymond F. 2000. Obsessive-Compulsive Aspects of Craving: Development of the Obsessive Compulsive Drinking Scale. Addiction, Vol. 95, pp. 211-217. http:// dx.doi.org/10.1046/j.1360-0443.95.8s2.9.x. 
Berry, John W. \& Poortinga, Ype H. \& Segall, Marshall H. \& Dasen, Pierre R. 2002. Cross-Cultural Psychology: Research and Applications. Cambridge: Cambridge University Press.

Bogoyavlenskiy, Dmitriy 2010. Russia's Indigenous Peoples of the North: A Demographic Portrait at the Beginning of the Twenty-First Century. Sibirica, Vol. 9, No. 3, pp. 91-114. Available at https://www.deepdyve.com/browse/journals/sibirica/2010/ v9/i3, last accessed on June 9, 2015.

Bogoyavlenskiy \& Pika 1991 = Bogoiavlenskii, Dmitrii \& Pika, Aleksandr. Nasil'stvennaia smertnost' u narodov Severa (na primere Kamchatki i Chukotki). [Mortality Caused by Violence among Arctic Peoples (on the Examples of Kamchatka and Chukotka).] In: A.I. Chistobaev (ed.) Raiony prozhivaniia malochislennykh narodov Severa. [Regions Populated by Small-Numbered Peoples of the North.] Geografiia i khoziaistvo, No. 4. Leningrad: Izd. Geograficheskogo obshchestva SSSR, pp. 162-182.

Chrzan, Janet 2013. Alcohol: Social Drinking in Cultural Context. New York: Routledge Chapman \& Hall.

Glasser, Irene 2013 [2011]. Anthropology of Addictions and Recovery. Waveland Press, Inc.

Islavin, Vladimir 1847. Samoedy $v$ domashnem i obshchestvennom bytu. [Samoyeds in Private and Social Life.] Sankt-Peterburg: Tip. Ministerstva gosudarstvennykh imushchestv. Available at http://webirbis.aonb.ru/irbisdoc/kr/2012/07kp138.pdf, last accessed on June 10, 2015.

Kertselli, Sergei 1911. Po Bol'shezemel'skoi tundre s kochevnikami. [A Trip across the Bolshezemelskaya Tundra with Nomads.] Arkhangel'sk: Gubernskaia tipografiia. Available at http://leb.nlr.ru/edoc/330600/, last accessed on June 10, 2015.

Klokov, Konstantin 1996. Kochevoe olenevodcheskoe naselenie: otsenka vozmozhnostei etnosotsial'noi adaptatsii $i$ razvitiia. [The Nomadic Reindeer-Husbandry Population of Russia: The Concept of Ethno-Social Adaptation and Development under Modern Conditions.] Sankt-Peterburg: NII Geografii Sankt-Peterburgskogo gos. universiteta. Available at http://www.arlis.org/docs/vol1/A/49219278.pdf, last accessed on June 10, 2015.

Kozlov, Andrei \& Vershubskaya, Galina \& Kozlova, Maria \& Shmitt, L. 2002. Modernizatsionnyi stress u korennogo naseleniia Severa Zapadnoi Sibiri. [ModernisationRelated Stress among the Aboriginal Peoples of Western Siberia.] Moskva: Institut Etnografii i Antropologii RAN.

MacAndrew, Craig \& Edgerton, Robert B. 2003 [1969]. Drunken Comportment: A Social Explanation. Clinton Corners, N.Y.: Percheron Press.

Maksimov, Sergei 1984. God na severe. [A Year in the North.] Arkhangel'sk: SeveroZapadnoe knizhnoe izdatel'stvo.

McKnight, David 2002. Anthropological Views of 'the Problem of Drinking'. In: From Hunting to Drinking: The Devastating Effects of Alcohol on an Australian Aboriginal Community. London \& New York: Routledge, pp. 10-19.

Modell, Jack G. \& Glaser, Frederick B. \& Cyr, Louis \& Mountz, James M. 1992a. Obsessive and Compulsive Characteristics of Craving for Alcohol in Alcohol Abuse and Dependence. Alcoholism: Clinical and Experimental Research, Vol. 16, No. 2, pp. 272-274. http://dx.doi.org/10.1111/j.1530-0277.1992.tb01375.x. 
Modell, Jack G. \& Glaser, Frederick B. \& Mountz, James M. \& Schmaltz, Stephen \& Cyr, Louis 1992b. Obsessive and Compulsive Characteristics of Alcohol Abuse and Dependence: Quantification by a Newly Developed Questionnaire. Alcoholism: Clinical and Experimental Research, Vol. 16, No. 2, pp. 266-271. http://dx.doi. org/10.1111/j.1530-0277.1992.tb01374.x.

Mukhachev, Anatoly 2001. Puteshestvie v mir olenevodov. [A Journey to the World of Reindeer Herders.] Novosibirsk: Nauka.

Nemtsov, Aleksandr 1997. Potreblenie alkogolia i smertnost'v Rossii. [Alcohol Consumption and Mortality in Russia.] Sotsiologicheskie issledovaniia, No. 9, pp. 113116. Available at http://ecsocman.hse.ru/socis/msg/269466.html, last accessed on June 10, 2015.

Penzel, Fred 2000. Obsessive-Compulsive Disorders: A Complete Guide to Getting Well and Staying Well. New York: Oxford University Press.

Pika, Alexander 1993. The Spatial-Temporal Dynamic of Violent Death among the Native Peoples of Northern Russia. Arctic Anthropology, Vol. 30, No. 2, pp. 61-76. Available at http://www.jstor.org/stable/40316338?seq=1\#page_scan_tab_contents, last accessed on June 10, 2015.

Pivneva, Elena 2005. Etnodemograficheskie aspekty problemy alkogolizma u malochislennykh narodov Severa. [Ethno-Demographic Aspects of the AlcoholismRelated Problems among the Small-Numbered Peoples of the North.] In: Elena Pivneva \& Dmitri Funk (eds.) V poiskakh sebia: narody Severa $i$ Sibiri v postsovetskikh transformatsiiakh. [Searching for Oneself: Peoples of the North and Siberia in Post-Soviet Transformations.] Moskva: Nauka, pp. 65-84.

Semke, Valentin \& Bohan, Nikolai 2008. Transkul'tural'naia addiktologiia. [Trans-Cultural Addictology.] Tomsk: Izdatel'stvo Tomskogo gosudarstvennogo universiteta.

Sidorov, Pavel \& Shubin, Sergei 1994. Etnicheskie osobennosti alkogol'nogo psikhoza $\mathrm{u}$ nentsev. [Ethnic Peculiarities of Alcoholic Psychosis among the Nenets.] Sotsiologicheskie issledovaniia, No. 7, p. 89. Available at http://ecsocman.hse. $\mathrm{ru} / \mathrm{text} / 18915231 /$, last accessed on June 10, 2015.

Zavjalov, Vladimir 1990. Clinical-Psychological Approaches to Alcoholism: Multiple Versions of Alcohol Dependence. In: Bernard Segal \& Caesar Korolenko (eds.) Addictive Disorders in Arctic Climates. New York: The Haworth Press, pp. 15-30. 